Portland State University

PDXScholar

1977

\title{
Social impact assessment at the neighborhood level
}

William H. Triest

Portland State University

Follow this and additional works at: https://pdxscholar.library.pdx.edu/open_access_etds

Part of the Community-Based Research Commons, and the Social Work Commons Let us know how access to this document benefits you.

\section{Recommended Citation}

Triest, William H., "Social impact assessment at the neighborhood level" (1977). Dissertations and Theses. Paper 1880.

https://doi.org/10.15760/etd.1879

This Thesis is brought to you for free and open access. It has been accepted for inclusion in Dissertations and Theses by an authorized administrator of PDXScholar. Please contact us if we can make this document more accessible: pdxscholar@pdx.edu. 
SOCIAL IMPACT ASSESSMENT AT THE

NEIGHBORHOOD LEVEL:

SALEM, OREGON

1977

by

WILLIAM H. TRIEST

A practicum submitted in partial fulfillment of the requirements for the degree of

MASTER OF SOCIAL WORK

Portland State University 


\section{ACKNOWLEDGEMENTS}

I would like to extend my gratitude to the many persons who assisted me in the completion of this project:

Dick Engstrom for his sponsorship as advisor, Grace Boys and Bill Hayden for the supportive roles they took in working with me, Nancy Koroloff for the time and insights into the assessment tool's development, to the members of the review committee for their participation in the difficult formulation of the paper's concepts, to friend Joe Gallegos for his review of the paper's ideas and format, and finally to Mary Dozark for her labor of typing. 


\section{FOREWORD}

In December of 1976 I was approached by the Director of the Salem Primary Prevention Project, Grace Boys, and asked if the development of a Mental Health Impact Statement would be of interest to me. As she explained it, the primary prevention project operating in conjunction with Marion County Community Mental Health, The City of Salem Community Development Department and Salem School District $24 \mathrm{~J}$, had as one of the project goals the creation of a tool to assess the mental health of the local community. My participation would, if approved, meet the requirements for a written practicum in partial fulfillment of the requirements for a Masters in Social Work degree at Portland State University. In addition this would be a contractual arrangement between myself and Marion County Community Mental Hea1th.

Several weeks passed while formal arrangements were being solidified, but by January 1977 my role as a student contractor was legitimized.

The following paper is the result of the research and exchange of ideas and information between myself, the Special Review Committee formed to assist in the tool's development, city, mental health and school district staff and various community individuals. 
Originally, it had been hoped that the assessment tool itself might be field tested prior to July of this year. Unfortunately that did not happen. However, plans have been arranged for the testing of this tool in one or more of the neighborhood areas in Salem. This will be valuable for the tool, since only by application can errors be eliminated and refinements gained.

Finally, with a great deal of humility, may I say that this test should only be viewed as a starting point towards the very difficult task of measuring the effects of planned changes upon social environments. Perhaps some of the tool's greatest value will lie in an increased sensitivity towards our manipulation of our own environments and greater allowance for the legitimate participation of neighborhood residents in the planning process. 
TABLE OF CONTENTS

PAGE

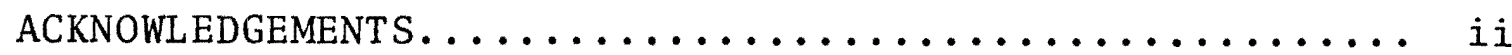

FOREWORD $\ldots \ldots \ldots \ldots \ldots \ldots \ldots \ldots \ldots \ldots \ldots \ldots \ldots \ldots \ldots \ldots \ldots \ldots \ldots \ldots \ldots$

PART I - NARRATIVE........................ 1

CHAPTER

I INTRODUCTION........................ 2

II REVIEW OF THE LITERATURE.............. 4

Mode1s of Social Impact Assessment......... 6

Causal Inference Model.............. 6

Systemic Analysis or Comparative

Diachronic Methodology............. 7

E-Mode1........................ 7

Correlation Analysis Model............ 7

Cost/Benefit Mode1................. 7

Critical Impact Area Analysis.......... 7

Elements of a Local. Impact Assessment....... 8

II TOWARD A RATIONALE FOR ASSESSMENT......... 10

Background Setting.................. 10

The Community as a System.............. 12

The Competent Community................. 15

Community We11-Being................. 16

Planning as a Partnership.............. 17

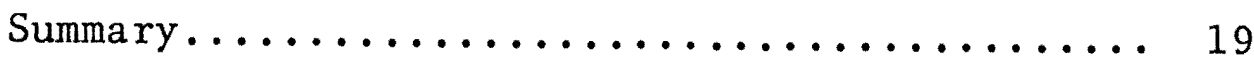

IV INDICATORS OF COMMUNITY WELL-BEING........ 20

Social Health..................... 20 
CHAPTER

Hetergeneity/Homogeneity............. 20

Stability....................... 21

Neighboring Functions................ 21

Community Problem-Solving............. 21

Physical Environment............... 22

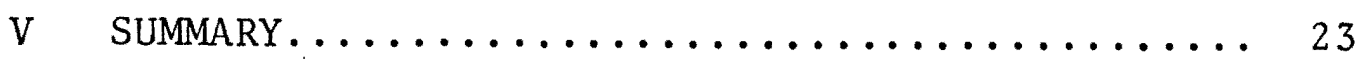

Limitations of Tool............... 23

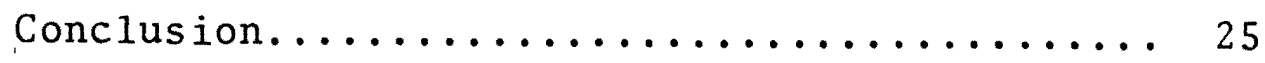

PART II - PROJECT EVALUATION TOOL.............. 26

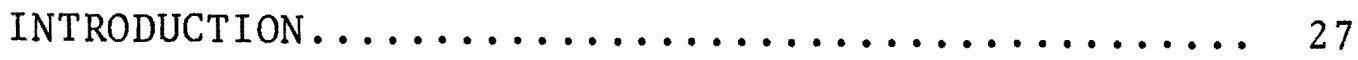

Criteria for Test................. 28

Procedure for Usage................. 29

Section A. Social Health............ 31

Section B. Heterogeneity/Homogeneity..... 35

Section C. Stability.............. 38

Section D. Neighboring Functions........ 41

Section E. Community Problem-Solving..... 44

Section F. Physical Environment....... 46

SURVEY FOR SECONDARY ANALYSIS............ 50

SURVEY............................. 51

I. Project Description.............. 51

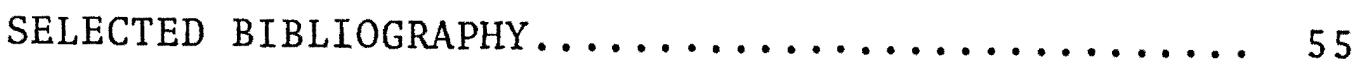

APPENDIX A - SOCIAL IMPACT REVIEW COMMITTEE MEMBERS.... 59

APPENDIX B - SOCIAL IMPACT REVIEW COMMITTEE MINUTES.... 60

APPENDIX C - FLOW CHART ASSESSMENT PROCESS.......... 73 
vii

PAGE

APPENDIX D - SALEM NEIGHBORHOOD GROUPS............. 74 
PART I

NARRATIVE 
CHAPTER I

INTRODUCTION

One of the most interesting things that has ever happened in the world was the western discovery that history is arbitrary and that societies are human, and not divine or natural, creations that we actually have the capacity of making choices in regard to our social systems.

We live in an age of increasing awareness of the effects of human manipulation upon the environment. We live in an age that a1so requests an increasing amount of local control over decisions that may effect residents. Finally, we live in an age that is interested in identifying and correcting mishaps that may occur through human planning efforts. This is the background setting for social impact analysis, i.e., a fairly recent outgrowth of the more commonly recognized environmental impact analysis.

This paper originated as a result of one of the stated objectives of the Salem Primary Prevention Project. That project, operating jointly with Marion County Community Mental Health, Salem School District $24 \mathrm{~J}$ and the City of Salem's Community Development Department, has had as one of its stated objectives, the development of a mechanism to review the impact of planned change at the local level.

\footnotetext{
${ }^{1}$ Peter Barry Chowka "The Original Mind of Gary Snyder" East West Journa1, Vo1. 7, No. 6, June 1977, P. 30.
} 
For several years both the staff and Advisory Committee for the Primary Prevention Program had wrestled with the complexity of developing such a review or assessment mechanism. Existing literature on social impact assessment appeared to deal primarily with rather large physical impacts upon local areas. Projects such as multiple-use resevoirs and inter-state highways that came under the construction auspices of the federal government are examples. Other sources of information on social impact assessment were still primarily building theory, attempting to sort out the maze of relationships between dozens of variables in the social structure. Very little has been developed in the way of actual assessment tools for local use. Finally, should someone start from scratch, the question arose - what do we want to measure; the health of individuals or the neighborhood? And what are the significant components of such an analysis?

This, then was the background for beginning the search to develop the social impact assessment tool in January of this year. It shall be the purpose of this paper to construct both a rationale and a method for assessment of planned changes from local units of government upon neighborhoods under their jurisdiction. 


\section{CHAPTER I I}

\section{REVIEW OF THE LITERATURE}

The formal assessment of significant public projects is a rather recent phenomena. Legislative action by Congress in 1969 created the better known National Environmental Policy Act of 1969 (Wolf, 1974). However, it was Section 122 of PL91-611 from the River and Flood Control Act of 1970 that gave Social Impact Assessment (SIA) its teeth (ibid.).

Specifically Section 122 offers the following operational definition of SIA:
Effect assessment is an iterative process which consists of the following steps: identification of anticipated project-caused economic, social, and environmental effects; quantitative and qualitative description and display of the ef- fects; evaluation of the effects, whether ad- verse or beneficial; and consideration of measures to be taken if a proposed project would cause adverse effects.

(Shie1ds, 1974)

The fundamental problem behind most assessment procedures is to examine the impact of planned change (technology) upon the environment. Thus, technology is viewed as effecting not only the natural environment but the economic and human or social environments as well. The latter has become the concern of SIA.

Oregon has been a leader in the utilization of SIA. 
In 1970 a report entitled Socio-Cultural Impacts of Watcr Resource Development in the Santiam River Basin was deve1oped (Hogg and Smith, 1970). The report startled some by concluding that this particular dam construction left the town (Sweet Home) with some rather negative impacts upon the social system.

In 1971, Oregon became the first state to test the requirement for social impact assessment in the Goose Hollow Foothills League $v$. Romney (Francis, 1974). The courts ruled that an impact statement for the proposed student high-rise apartment in a low-rise neighborhood must be filed to assess the impact of neighborhood character, traffic congestion and scenic views (Ibid.).

The first task for most of the researchers has been the isolation of the social from the general environmental impacts. Several definitions may be considered. Gardner (1973) talks of changes in the activity or interaction of units as a response to changes from the surrounding environment. Mack (1974) distinguishes social from economic impacts as "impacts on people other than those that operate primarily via the dollars in their wallets." Another writer thinks of social impacts as

changes in interpersonal relationships, perceived well-being, or quality of life which might be attributed directly or indirectly to the construction of a project. (Lleweliyn, 1974)

Perhaps the easiest definition to grasp is given by Shields 
(1974) who labels social impact as "anything which effects a change in the state of a social system or its subsystems." It is becoming apparent that social impact assessment along with environmental and economic impact assessment are developing into tools for planning in an attempt to forecast the effects of our planned change before we act. We may view this as consequential planning.

Naturally we can see that there is an overlap between the effects within our physical, social, and economic environments; it is the separation of each in order to more fully evaluate impacts that is difficult.

During the last several years Social Impact Assessment has begun to develop into a new state of art. At this point there appears to be no formal, rational methodology that stands head and shoulders above the rest. C. P. Wolf (1974) writes,

to all appearances SIA is still in the 'natural history' stage of science-building, at a point far removed from the mature stage of deductively formulated theory.

Mode1s of Social Impact Assessment

A review of SIA literature and methodology reveals a variety of styles of assessment. An outline of the various categories is presented below.

Causal Inference Model (Burdge and Ludtke, 1973). This approach makes causal inferences from interviews with impacted residents. Its analysis, therefore, is primarily 
subjective.

Systemic Analysis or Comparative Diachronic Methodo-

logy (Dunning, 1974; Johnson and Burdge, 1974). This method utilizes comparisons of baseline data between current data and forecasted data as a result of project impact. A methodology comparing impact area existing and projected baseline data with a closely resembling area already impacted by a similar project.

E-Mode1 (Mack, 1974). This model, unique in itself, has derived a criteria of assessment placing desirability of benefits not in dollar terms but at the level of human want and needs as defined by the cultural setting. Different categories of well being are given and maximizing utility is reached by obtaining the highest score possible in all categories of well-being.

Correlation Analysis Mode1 (James and Brogan, 1974; Llewellyn, 1974). This model attempts to analyze impact effects between variables in special case studies. An example is the correlation analysis used by James and Brogan between open space (parks) and community we11-being, using crime and physical environment as indicies.

Cost/Benefit Mode1 (Peele, 1974). This model attempts to arrange the effects of project impact into social benefits and cost, thereby weighing the total outcome.

Critical Impact Area Analysis (Christensen, 1976). The criteria for utilizing this approach depends upon the 
project falling within very specific boundaries. Seven impact areas such as recreational patterns, shopping opportunities and personal safety are used.

Currently, the major methodologies of SIA have certain restrictions. First, they have been developed predoininately for assessment of 1 arge physical projects such as multipleuse reservoirs. Since impact projects such as these originate with the federal government, they tend not to have much applicability with local governmental impact projects.

Second, certain methodologies deal only with very narrow criteria, because of the difficulty of assessing the interaction of multiple variables.

Finally, most of the existing impact assessment methods tend to avoid investigation of such social fabric elements as community organization and community networks. The emphasis is still heavily upon physical changes to the neighborhood.

Elements of A Local Impact Assessment

As a conclusion to the investigation of current social impact assessment, it will be helpful to identify desired elements of an assessment tool for our purposes. In outline form they would be:

1 - A combination of indicators that reflect the community social structure.

2 - An ability to measure programing (projects) as wel1 as policy. 
3 - A comparative assessment between scenarios of impact with and without the project.

4 - Reflect differential impacts; i.e., the varying degrees of impact upon different categories of residents within the impact area. 
CHAPTER III

TOWARD A RATIONALE FOR ASSESSMENT

\section{Background Setting}

In order to solicit the thinking and feelings of the participating agencies of the Primary Prevention Program, a special committee, composed of representatives from those organizations and representatives from several of the neighborhood associations was formed. This committee, known as the Social Impact Review Committee, met periodically with the author throughout the six months of development of the final tool.

One of the results from these meetings was the following set of guidelines pertaining to the actual tool itse1f. Listed briefly, they are as follow:

1 - Scaled to application within the local level.

2 - Identifiable linkage to the concept of primary prevention in mental health.

3 - General simplicity in design and administration for utilization by city staff relating to time and cost effectiveness and,

4 - Ease of basic understanding for utilization with neighborhood residents.

Each of these criteria require some explanation. 
First, it will be important that the final tool is applicable to the local situation; in this instance meaning, the impact of local units of government policy and programing upon the community of Salem and/or its sub-units, city neighborhoods. Since federal law already requires environmental (including social) analysis there is little justification in duplication of that process. Rather, the concern here is the analysis of impact of the more routine programs and policy that occur throughout the year; programs instigated by the city or other local public agency. Examples of such programs might be neighborhood parks or major street alterations. An example of policy might be a zoning change. Second, the tool should show a logical linkage to the concept of primary prevention. Primary prevention may be defined as the "...promotion of healthy physical, social and biological environments.." (Human Resources Subcommittee, 1976). Thus we should be attempting to measure the impact upon social health, in this case, as one of the steps toward its promotion.

Third, the tool must be simple enough, without losing effectiveness, in order that time and money allow it to be actually utilized by city staff as part of the routine planning process.

Finally, it is hoped that the tool itself will be not only available to, but utilized by neighborhood groups along with city planning staff. This will mean a format unriddled 
with academic terminology and complicated procedures for the vast majority of people who are currently non-experts in the field of social impact assessment.

Having identified certain criteria developed by the Review Committee, I sha11 now outline and then discuss some general frameworks of reference that permit a basic rationale for the assessment tool. These reference frameworks are; the community as a system, the competent community, communit well-being as a goal and planning as a partnership.

The Community As A System

Systems analysis has been in vogue for several decades, most notably in the hard sciences, since von Bertalanffy (1969) developed his theoretical framework around analysis of the biological sciences. More recently the general principles of interdependence, system maintenance and boundaries have been widely applied to the social sciences, most notably urban studies (Cousins, 1970). The idea of cities ecosystems (Steiss, 1974) input-output analysis borrowed from economic theory, social networks (Bell and Newby, 1972) and, theories of social systems change (Warren, 1969).

For purposes of this paper two concepts from general systems analysis are useful.

First the Holon Concept depicts any system as having various component subsystems which have a potentially definable relationship with each other. If part of the sub- 
system is disrupted, the effects, like ripples on a pond, will radiate out to each and every other subsystem or parts (Weinberg, 1975). Therefore both theory and common sense tell us why functional sickness in one part of the city such as a ghetto or perhaps a functional area such as the political subsystem will eventually spread its impact to the rest of the city's communities or parts.

The second important concept to be utilized concerns viewing the system as open with exchanges across its boundaries primarily for purposes of system maintenance in order that the system survive by requisitioning needed components for its livelihood (Katz and Kahn, 1966). To explain this more clearly let us view residential neighborhoods as small systems, by themselve's, but dependent upon the larger community (city) for exchanges, such as employment for survival. Systems analysis, then, stresses relationships, exchanges and interdependence among not only components of the system but between the system and its larger environment. In utilizing this particular analytical approach for assessing the impact of planned change it will be necessary to remember that there is an interrelationship between components of the system such as a neighborhood and the larger community, or between the physical and social environment of a neighborhood.

Having identified several useful aspects of systems for analytic purposes the next consideration needs to be 
the selection of the unit of analysis; $i . e$. , what are the boundaries of our system?

Controversy continues upon the definition and role of urban communities and their sub-units, the neighborhood. Writers and researchers in sociology have not only greatly disagreed upon their definition but stated that they no longer exist as we traditionally think of them. Perhaps we have created an obstacle for ourselves by trying to measure a moving object. It would appear that the nature and workings of communities is changing. Roland Warren is one example of modern sociologists who depicts the nature of our local community structure changing from local area organization (horizontal axis) to specific interest group organization (vertical axis), (1969).

Other writers are still finding that certain key identifications by residents within cities of both felt and visible or physical barriers contribute toward a sense of neighborhood or residential community (Ross, 1962; Greer, 1974). Again, the primary concern is the element of how local residents perceive their own neighborhood boundaries (Ittelson, 1973).

For the task at hand let us define the City of Salem as the system and the defined boundaries of the fourteen Salem neighborhoods, established jointly through community planning sessions by area residents and city planning staff, as sub-units or sub-systems. The advantage to this approach 
is that it not only meets the criteria of felt, established boundaries, but it allows the utilization of the final tool within the existing neighborhood organizations.

The Competent Community

In a paper dealing with the prevention of mental disorders, George Caplan (1974) speaks of preventative psychiatry as reducing the incidence of mental disorder.. "by combating harmful forces in the community and strengthening the capacity of the people to withstand stress". In another article by the same author entitled "Conceptual Models in Community Mental Health", the model of community organization and development is discussed (Caplan, 1974). Basically, Caplan discusses the merits of a well organized community being better able to withstand the risks of mental disorder. The important concepts here are; viewing the desirable community as a competent problem-solving organization with humanistic values, a leadership and follower structure and methods to identify and resolve problems.

Other writers on community research have identified that the basic organization (intergration) of a community is perhaps the best indicator of its state of mental health (Leighton, 1963). In an article entitled Community Psychology and the Competent Community, Ira Iscoe states that the competent community utilizes internal or external resources including its human members to actively cope with problems that arise (Iscoe, 1972). 
Much of the theory of the competent community suggests a parallel with the theories of community organization by Murray Ross (1962) and Ronald Lippitt (1958). Both writers have stressed the development of indigenous capacity to develop problem-solving skills in order to internally determine community values and issues.

Community We11-Being

aut of recent environmental impact assessment studies has come the concept of community well-being. Some would define it as a sense held by area residents that all is well (James, et al, 1974; Wolf, 1974). For our purposes we may define community well-being as a dynamic condition connotating health, happiness and prosperity potentially measurable by either the $1 \mathrm{ack}$ of social dysfunctions, such as crime and mental disorders, or social health, as evidenced through achievement and excellence.

Community well-being can be operationally defined by indicators that show things are well or things are not well within the community ( $I b i d$ ). The evidence may be seen and measured by symptoms of either health or sickness, such as social discord or diagnosed mental problems. More than providing an analytical toe-hold, the rationale of community we11-being provides a goal.

Community We11-being (CWB) and the competent community together can portray a goal for the healthy urban system. First, the competent community would indicate an active 
posture of problem-solving and leadership. CWB, on the other hand, examines the community as it currently exists in reaction to its environment.

\section{P1anning As A Partnership}

The idea of citizen participation is a little like spinach: no one is against it in principle because it is good for you.

\section{Anonymous}

As a final criterion for the assessment tool the involvement of local residents needs to be considered. Citizen involvement is no longer a luxury consideration in Oregon. In 1973 the State Legislature adopted Senate Bil1 100 (ORS Chapter 197), commonly known as the 1973 Land Use Act. Under this piece of legislation citizen involvement in a11 governmental units as an on-going process is mandated (LCDC, 1974).

The difficulty in citizen involvement has become a question of operationalizing the intent. As the introductory quotation implies, few people in a democratic society would oppose citizen involvement, but where does one draw the line between staff and citizen input in the planning process? In an article entitled "Toward a Theory of. Guided Societal Change", Amitai Etzioni speaks of agreements or consensus-building between member units, in this case, neighborhoods, and the larger social units, such as the city management :

As we see it, however, when a cybernetic model is applied to a social unit, it must be taken into 
account that, for both practical and ethical reasons, the member unit which does the work cannot be coerced to follow "signals" unless they are, at least to some extent, responsive to the member's values and interests. Hence, the downward flow of control signals must be accompanied by an upward flow and a "lateral" (intermember) flow which express what the members wish or are willing to do. We refer to these flows as consensus-building, and to the combination of control and consensus building, the societal cybernatorial mechanisms, as social guidance... only a balanced tension between society and state, each one guarding its autonomy, allows the operation of relatively responsive and active societal guidance. (1968) (Emphasis the author's)

If it is important for "signals" to flow not only downwards but upwards within the societal structure then an agreement for such to happen would be an important starting point.

The City of Salem identifies one option of planning as a "shared responsibility" between neighborhood planning organizations and city planning staff (Hayden, Schwartz, 1975). This would coincide with certain writers' identification of planning as a shared process between citizens and power holders. Citizen involvement in public planning and decision-making has been likened to levels or rungs on a ladder; beginning with non-participation, taking the form of manipulation through tokenism, to ultimate citizen control. Under the level of partnership, the lowest level of citizen power, we see an

...agreement to share planning and decisionmaking responsibilities through such structures as joint policy boards, planning committees and mechanisms for resolving impasses.

(Arnstein, 1969) 
This shared responsibility or "partnership" works best, it is felt, when the community itself has organized powerbases to which citizen leaders are accountable (Ibid.).

Summary

The final assessment tool will be based upon not only the criteria mentioned at the beginning of this chapter, but the criteria just discussed. The tool will follow the concepts of systems analysis regarding inter-related parts, the competent or problem-solving community, community we11being (a hypothetical goal determined by indicators of such) and an assessment process based upon a partnership between the citizens effected by a proposed project and city planning staff. 


\section{CHAPTER IV}

\section{INDICATORS OF COMMUNITY WELL-BEING}

Research into potential indicators of community wellbeing has given a variety of possible criteria for evaluation of a community's position as to its health or nonhealth. For the purpose of this tool the following categories of indicators have been selected; Social Health, Heterogeneity/Homogeneity, Stability, Neighboring Functions, Community Problem-Solving and Physical Environment. A short review of these terms follows.

\section{Social Health}

This term is defined as the relative absence of high risk indicators (Brogan, 1974). Examples of traditional high risk indicators are crime, mental disorder and drug and alcohol abuse. The position assumed here is that the healthy community will have a low incidence of high risk indicators.

\section{Hetergeneity/Homogeneity}

This term is defined as the degree to which community population and lifestyles are similar or dissimilar (Planning Environmental Internation, 1975). Traditional population demographics available from United States census data are utilized. The objective here is not to necessarily place a 
value judgement on one settlement pattern by itself but to assess the current community situation with a projected pattern, in order to assess the impact upon existing lifestyles.

$\underline{\text { Stability }}$

Here the term is defined as the degree to which the community remains the same over the years (James, et al, 1974). The emphasis is upon knowing the historical trend of the community population and mobility. The assumption is that stable communities have a greater capacity for disruptive influences than unstable communities.

\section{Neighboring Functions}

This term is defined as the amount of neighboring functions and communications between individuals and groups within the community. It is based upon research which indicates that neighborhoods contain natural helping networks and that the development and sustenance of such is intregal to the collective health of the community (Collins, Pancoast, 1976).

Community Problem-Solving

The definition for this term is the level of community skill and vitality at solving local problems. The assumption is that the healthy community will have a developed capacity to address and resolve issues confronting it, as such it takes an active versus reactive stance and increases 
its coping ability (Iscoe, 1972).

Physical Environment

This term is defined as the major indicators of the material quality of the community. Here the assumption is upon the interrelationship between the quality of such indices as housing, streets, parks and the social health of the community (Brogan, 1974). 


\section{CHAPTER V}

\section{SUMMARY}

Before leaving this first section on background theoretical material for the tool's basis a summary of the tool's general utilization process and limitations is needed.

First, regarding utilization, the test has been developed for usage by the City of Salem's Community Development Department to assess city or other local public project effects upon the city's neighborhoods. It is recommended that city staff administer the test with both assistance and ongoing knowledge and approval of the residences potentially effected by the project.

The latter is important. Part of the underlying assumption in the competent community is an ability to participate, if not control, decisions effecting its geographic rea $1 \mathrm{~m}$.

\section{Limitations of Tool}

In the space of one hundred and seventy-six years the Lower Mississippi has shortened itself two hundred and forty-two miles. That is an average of a trifle over one mile and a third per year. Therfore, any calm person, who is not blind or idiotic, can see that in the 01d Silurian Period, just a million years ago next November, the Lower Mississippi River was upward of one million three 
hundred thousand miles long, and stuck out over the Gulf of Mexico like a fishing rod. And by the same token any person can see that seven hundred and forty-two years from now the Lower Mississippi will be only a mile and threequarters long, and Cairo and New Orleans will have joined their streets together, and be plodding along under a single mayor and mutual board of aldermen. There is something fascinating about science. One gets such wholesome returns of conjecture out of such a trifling investment of fact.

Mark Twain, Life on the Mississippi

Regarding limitations of the assessment tool, probably the most important consideration will be to remember that final scores are not reflections of hard or scientific data. The tool's process is one of transferring raw subjective data into abstract logical numbers. This gives a systematic approach to the analysis, but final assessment scores should not be translated as scientific fact. Another limitation to the tool is its emphasis upon the local urban community or neighborhood. This was done by choice but should be remembered if it is applied outside of city boundaries.

Finally, it must be remembered that the given indicators of community we11-being are not the only elements of our very intricate urban social systems. Social impact assessment is stil1 in its infancy stage, and many authors are still searching for the right combination of handles to assess the social environment. This tool is merely another attempt at an assessment model. 


\section{Conclusion}

In conclusion, it will be interesting to speculate that the next decade will see an attempt to synthesize at least three of the major evaluation criteria of man's impact upon the (total) environment; i.e., social, economic and environmental impact assessment. Most likely, only when all three impacts are seen as being interrelated and essential will those who plan and the recipients of those plans gain the full insights into their respective manipulations. 
PART II

PROJECT EVALUATION TOOL 


\section{INTRODUCTION}

The purpose of the evaluation tool for community we11being is to provide a mechanism for local municipalities (in this instance the City of Salem) to assess the impact of city programs and policy upon neighborhoods that would be effected by such actions.

This will require additional work for city planning staff prior to the implementation of certain projects, yet there are benefits to be gained.

First, the evaluation procedure for impact assessment utilizes joint participation between city planning staff and neighborhood associations, which, in itself, can increase the capacity of the local community to self-analyze situations effecting this area. In addition, such a partnership approach allows the neighborhood to come into closer contact with the difficulty of sorting out conflicting demands in public planning. The increased communication can lead to better relations and awareness of needs for both neighborhood persons and city staff.

Other benefits to be derived from the assessment process are guideposts towards the development of worthwhile project alternatives when evaluation suggests the need for modification.

This particular test has been designed to measure 
potential impact of city projects upon certain aspects of a neighborhood's social system. It will not measure the impact of a project upon all elements of the social system but, rather, those identified as key towards the adequate functioning or well-being of a neighborhood.

For the purposes of this test, the term neighborhood shall refer to all identified planning areas utilized by the City of Salem Community Development Department. The test may be utilized for assessing the impact upon part of a neighborhood, the full boundary area or several neighborhoods.

Criteria For Test

The following criteria are suggested for selection of city projects to undergo analysis.

1 - Project is public (i.e., city, county, etc.)

2 - Project with budget size over $\$ 10,000$.

3 - Project will bring about permanent or long-lasting versus temporary change to impact area.

4 - Project will effect groups of people or neighborhood area versus a single individual or family.

5 - Project has certain visibility either real or imagined.

No set of criteria will adequately cover all situations, therefore, use of common sense and individual judgement is encouraged for the screening process of assessment selection. 
Procedure For Usage

The evaluation tool has been developed primarily for utilization by the city but may be also used by other public agencies such as school districts or county agencies. Application of the tool is meant to be utilized by the City Community Development Department in joint participation with a chosen representative of the impacted neighborhood; this may be a neighborhood counselor. Below, an outline of the procedure for usage follows.

1. Screening of projects; selection of projects meeting evaluation criteria by city staff.

2. Site visitation by Planning Staff to familiarize selves with impact area.

3. Primary analysis of project impact by City Staff. Review of analysis with neighborhood associations or other formal neighborhood group.

4. If required, secondary analysis by City Staff, with regular communication with and assistance, where desired, from neighborhood representative. Secondary analysis requires either a representative neighborhood survey by mail or personal interview $\underline{O R}$ public hearing in the neighborhood. The survey format is found at the end of the test section.

5. Final review of the survey analysis with the neighborhood residents by City Staff. 
6. Project reservation level in all cases is scoring below 2.0. This should indicate to City Planning Staff that definite reservations are indicated on behalf of the project's impact upon the health of the community's social system. Modifications of the project to minimize detrimental impacts would be in order. A scoring of below 2.0 in all sections should raise serious doubts as to the feasibility of the project concerning the social impacts. 
Section A. Social Health

1. Operational Definition

2. Goa1

3. Impact of Concern

4. Scale of Impact

5

2

1

The relative absence of high risk indicators such as crime and mental disorders.

The relative absence of high risk indicators such as crime and mental disorders.

Will the project contribute to a change in community health?

The project will significantly improve the social health of the community, as measured by a reduction in the incidence of high risk indicators.

The project will minimally improve the social health of the community.

Neutral effect from project.

The project will minimally increase social dysfunction, as indicated by an increase in high risk indicators.

The project will significantly increase social dysfunction, as indicated by an increase in high risk indicators.

5. High Risk Indices

Data Source

Rank

A-1 High School Dropouts

School District

$\begin{array}{lllll}1 & 2 & 3 & 4 & 5\end{array}$

A-2 High School Absenteism

School District

$\begin{array}{lllll}1 & 2 & 3 & 4 & 5\end{array}$ 
5. High Risk Indices (Continued)

A-3 Juvenile Arrest

A-4 Child Court Supervision

A-5 Homocide Involvement

A-6 Burglary Involvement

A-7 Narcotics Arrests

A-8 Suicides

A-9 Percent Unemployed

A-10 Percent ADC Caseload

A-11 Percent Low Income

Families and Individuals

A-12 Percent of Released Institutionalized persons residing in neighborhood
Marion County Juvenile Department

Marion County Juvenile Department

City of Salem Police Department

City of Salem Police Department

City of Salem Police Department

City of Salem Police Department

Marion County Employment Department

Marion County Public Welfare Dept.

U. S. Census

Marion County Community Mental Health $\begin{array}{lllll}1 & 2 & 3 & 4 & 5\end{array}$

$\begin{array}{lllll}1 & 2 & 3 & 4 & 5\end{array}$

$\begin{array}{lllll}1 & 2 & 3 & 4 & 5\end{array}$

$\begin{array}{lllll}1 & 2 & 3 & 4 & 5\end{array}$

$\begin{array}{lllll}1 & 2 & 3 & 4 & 5\end{array}$

$\begin{array}{lllll}1 & 2 & 3 & 4 & 5\end{array}$

$\begin{array}{lllll}1 & 2 & 3 & 4 & 5\end{array}$

$1 \quad 2 \quad 3 \quad 4 \quad 5$

$\begin{array}{lllllll}1 & 2 & 3 & 4 & 5\end{array}$

$\begin{array}{lllll}1 & 2 & 3 & 4 & 5\end{array}$

6. Primary Analysis

a. Site visitation by planning staff to familiarize itself with impact area.

b. Using the listed indices for health, develop a profile of the community trends of high risk indicators. Begin with 1960, then 1970, current year, ten year forecast without project and finally ten year forecast with project. If certain historical data for indices is unavailable utilize other years to develop at least two, preferably three, quantitative figures to project the trend. If relatively accurate data is unavailable for the indices do not utilize. 


\section{SAMPLE}

A-1 High School Dropouts

$\begin{array}{llr}\cdot 1960 & \text { Data } & 12 \\ .1970 & \text { Data } & 16 \\ \text {-1977 } & \text { Estimate or Actual Data } & 20 \\ \text { - } 1987 & \text { Estimate without project } & 27 \\ \text { - } 1987 & \text { Estimate with project } & 32 \\ \text { - Difference } & & +5 \\ \text { - Percentage } & & +18.5 \%\end{array}$

c. Using the criteria below rank each indice as to the percentage change in the estimate of the Project Forecast over the Trend Forecast.

Rank

5 More than a $10 \%$ reduction over trend

4 Less than a $10 \%$ reduction over trend

3 No change

2 Less than a $10 \%$ increase over trend

1 More than a $10 \%$ increase over trend

d. Total the indices; compute the average ranking and refer to the scale of impact.

e. If the average ranking is 2.0 or less proceed with secondary analysis.

7. Secondary Analysis

a. Community survey of impact area or public hearing at neighborhood association meeting; collection of residents' perceived analysis of impact. Rate collec- 
7. Secondary Analysis (Continued)

tive judgements according to the scale of impact and average with forecast trends, giving equal weight to each.

8. Project Reservation Level

Scoring below 2.0 . 


\section{Section B. Heterogeneity/Homogeneity}

1. Definition

2. Goa1

3. Impact of Concern

4. Scale of Impact

5

4

3

2

1
The degree to which community population and lifestyles are similar or dissimilar.

Self determination of the community settlement pattern.

Will the project change the character of the community in terms of the distribution of income, age or racial groups?

If a change occurs what will the magnitude and rapidity of it be?

The project will allow community self determination in an existing heterogenous community.

The project will allow community self determination in an existing homogenous community.

Neutral effect from project.

The project will not allow community self determination in an existing heterogenous community.

The project will not allow community self determination in an existing homogenous community. 
5. Homogeneity/Heterogeneity Indices

B-1 Community Income Distribution

B-2 Community Racial Distribution

B-3 Community Age Distribution

B-4 Community Religious Distribution

\section{Polk Data}

U. S. Census

U. S. Census

Council of Churches

6. Primary Analysis

a. Site visitation by planning staff to familiarize itself with impact area.

b. Develop a profile using preceding indices for heterogeneity/homogeneity. Following procedures outlined in Section A - Social Health, Primary Analysis, $6 . b$.

c. If the project will have no significant impact upon the community settlement pattern, (Less than $10 \%$ average change plus or minus from the trend), rank it 3.0 .

d. If the project estimates show any impact other than neutral, proceed with secondary analysis.

7. Secondary Analys is

a. Community survey of impact area or public hearing at neighborhood association meeting; collection of residents' perceived analysis of impact and approval or rejection of project. 


\section{Secondary Analysis (Continued)}

b. Ranking of perceived impact:

- If residents in a heterogenous community feel the project is acceptable rank it 5 .

- If residents in a homogeneous community feel the project is acceptable rank it 4 .

- If residents feel project will not effect them rank it 3 .

- If residents in a homogeneous community feel the project is unacceptable rank it 2 .

- If residents in a heterogeneous community feel the project is unacceptable rank it 1 .

8. Project Reservation Leve1

Scoring below 3.0 . 
Section C. Stability

1. Operational Definition

2. Goal

3. Impact of Concern

4. Scale of Impact

5

3

2

1
Degree to which the community demographic profile remains the same over the years.

To maintain the general community quality and soundness of the social environment.

How will the project effect the stability of the community?

The project will maintain the community's social environment.

The project will slightly change the community's social environment.

The project will moderately change the community's social envi ronment.

The project will significantly change the community's social environment.

The project will drastically change the community's social environment. 
5. Stability Indices

C-1 Residency turnover

C-2 Displacement of Residents

C-3 Business turnover

C-4 Community Population

Trends

- General Population Increase or Decrease

- Community Age Profile

- Community Sex Profile

- Community Family Profile

- Community Racial Profile

- Community Income Profile
Polk Data

Community Development Department

Polk Data

U. S. Census

U. S. Census

Section B

Section $B$

Section B

Section B

Section B $\begin{array}{lllll}1 & 2 & 3 & 4 & 5\end{array}$

$\begin{array}{lllll}1 & 2 & 3 & 4 & 5\end{array}$

$\begin{array}{lllll}1 & 2 & 3 & 4 & 5\end{array}$

$1 \quad 2 \quad 3 \quad 455$

$\begin{array}{lllll}1 & 2 & 3 & 4 & 5\end{array}$

$\begin{array}{lllll}1 & 2 & 3 & 4 & 5\end{array}$

$\begin{array}{lllll}1 & 2 & 3 & 4 & 5\end{array}$

$\begin{array}{lllll}1 & 2 & 3 & 4 & 5\end{array}$

$\begin{array}{lllll}1 & 2 & 3 & 4 & 5\end{array}$

$\begin{array}{lllll}1 & 2 & 3 & 4 & 5\end{array}$

6. Primary Analysis
a. Site visitation.
b. Using the indices given, develop a profile as in previous sections.
c. Using the criteria below rank each indice as to the percentage change in the estimate of the Project Forecast over the Trend Forecast.


6. Primary Analysis (Continued)

\section{Rank}

$5 \quad$ No change over trend

4 Less than $5 \%$ change over trend

3 Between 5 and $10 \%$ change over trend

2 Between 10 and $25 \%$ change over trend

1 Over $25 \%$. change over trend

d. Total the indices; compute the average ranking and refer to the scale of impact.

e. If the average ranking is less than 2.0 proceed with secondary analysis.

7. Secondary Analysis

a. Community survey of impact area or public hearing at neighborhood association meeting; collection of residents perceived analysis of impact.

b. Total the survey or public hearing results and average with primary analysis.

\section{Project Reservation Level}

Below 2.0. 


\section{Section D. Neighboring Functions}

1. Operational Definition The amount of neighboring functions and communication between individuals and groups within the community.

2. Goa1

The enhancing of neighboring functions and communication between individuals and groups.

3. Impact of Concern

Will the project effect the interpersonal exchange of the community?

4. Scale of Impact

5

4

3

2

1
Project will significantly increase neighboring functions

Project will slightly increase neighboring functions

Neutral effect from project

Project will slightly detract from neighboring functions

Project will significantly detract from neighboring functions

5. Indices

\section{Data Source}

Community Survey

bors on a regular basis (number and frequency)

D-2 Tools shared with neighbors on a regualr basis (number and frequency)
Community Survey

$\begin{array}{lllll}1 & 2 & 3 & 4 & 5\end{array}$ 
5. Indices (Continued)

Data Source

Community Survey

on a regular basis (number and

frequency)

D-4 Social entertainment with neighbors

on a regular basis (number and frequency)

\section{Primary Analys is}

a. Site visitation by Planning Staff.

b. Using the ranking below and the indicators of neighboring functions as guides, determine the scale of impact of the project.

- If the project will develop major neighborhood facilities or programs rank it 5 .

(EXAMPLE - neighborhood park or establishment of neighborhood association)

- If the project will develop minor neighborhood facilities or programs rank it 4 .

(EXAMPLE - through-street detours or day care program)

- If the project will have no significant effect upon neighboring functions rank it 3 .

- If the project will tend to inhibit neighboring functions rank it 2 . (EXAMPLE - A significant change one or more of the population demographics; refer to Section C.)

- If the project will drastically effect the physical or population demographic pattern of the neighborhood rank it 1 .

(EXAMPLE - Division of the neighborhood by a major thoroughfare or over $25 \%$ change in any of the population demographics.) 
6. Primary Analysis (Continued)

c. If the scale of impact is 2.0 or lower proceed with Secondary Analysis.

7. Secondary Analysis

a. Same as preceeding sections.

b. Same as preceeding sections

8. Project Reservation Leve1

2.0 or lower. 


\section{Section E. Community Problem-Solving}

1. Operational Definition The level of community skill and vitality at solving local problems.

2. Goa1

A high level of community problem-solving ability.

3. Impact of Concern

Project would detract from local problem solving.

4. Scale of Impact

4

3

2

1
Project will significantly increase community problem solving

Project will slightly increase community problem solving

Neutral effect from project

Project will slightly detract from community problem solving

Project will significantly detract from community problem solving

5. Primary Analysis

a. Answer the following questions regarding the project:

- Project will allow the continuation of existing neighborhood meeting/ gathering space

Yes No

- Project will allow for indigenous decision-making regarding project outcome or direction Yes_No 
5. Primary Analysis (Continued)

- Project will identify and staff person to be accessible to neighborhood groups for information relating to project development

Yes No

- Project will support and encourage full neighborhood participation in decision-making relating to project development

Yes No

b. Rank answers according to following:

$\underline{\text { Rank }}$

5 YES answer for all four questions

4 YES answer for three questions

3 Two YES, Two NO

2 No answer for three questions

$1 \quad$ No answer for all four questions

c. The ranking equates with the scale of impact if 2.0 or lower provide Secondary Analysis.

6. Secondary Analysis

a. Community survey or public hearing (refer to Section E, survey questions)

b. Tally survey and rank according to Scale of Impact.

7. Project Reservation Level

Scoring below 2.0 


\section{Section F. Physical Environment}

\section{Operational Definition}

The major indicators of the material quality of the community

2. Goa1

The improvement of the material quality of the environment

3. Impact of Concern

Project would detract from the material quality of the environment

4. Scale of Impact

5

4

3

2

1
Project will significantly enhance the material quality of the community environment

Project will slightly enhance the material quality of the community environment

Neutral effect from project

Project will slightly detract from the material quality of the community environment

Project will significantly detract from the material quality of the community environment

5. Indices

Data Source

\begin{tabular}{|c|c|c|c|}
\hline$F-1$ & Percent deteriorated homes & U. S. Census & $\begin{array}{lllll}1 & 2 & 3 & 4 & 5\end{array}$ \\
\hline$F-2$ & $\begin{array}{l}\text { Percent residences lacking } \\
\text { plumbing }\end{array}$ & Housing Survey & $\begin{array}{lllll}1 & 2 & 3 & 4 & 5\end{array}$ \\
\hline$F-3$ & $\begin{array}{l}\text { Percent housing over- } \\
\text { crowded (greater than } \\
1.01 \text { persons per room) }\end{array}$ & Housing Survey & $\begin{array}{lllll}1 & 2 & 3 & 4 & 5\end{array}$ \\
\hline
\end{tabular}


5. Indices (Continued)

Data Source

$\underline{\text { Rank }}$

F-4 Percent unpaved streets Pub1ic Works

1. $2 \begin{array}{llll}2 & 3 & 4 & 5\end{array}$

in community

F-5 Traffic F1ow

Pub1ic Works

$\begin{array}{lllll}1 & 2 & 3 & 4 & 5\end{array}$

F-6 Street Lighting

Pub1ic Works

$\begin{array}{lllll}1 & 2 & 3 & 4 & 5\end{array}$

F-7 Nuisance Complaints

Police Department

$\begin{array}{lllll}1 & 2 & 3 & 4 & 5\end{array}$

F-8 Percent of houses three

Community Development Department

$\begin{array}{lllll}1 & 2 & 3 & 4 & 5\end{array}$ or more blocks from public transportation

F-9 Ratio of parks and open Parks Department space to community population

F-10 Ratio of neighborhood primary consumer services (banks, grocery stores, service station, day care facilities)

6. Primary Analysis

a. Rank the physical environment indices F-1 through F-8 accordingly:

$\underline{\text { Rank }}$

5 Over $10 \%$ reduction in the level of occurrence between current figures and future estimates as a result of the project 
6. Primary Analysis (Continued)

$\underline{\text { Rank }}$

4 Up to $10 \%$ reduction in the level of occurrence between current figures and future estimates as a result of the project

3 No change in indices as a result of the project

2 Up to a $10 \%$ increase in occurrence level between current figures and future estimates

1 Less than a $10 \%$ increase in occurrence level between current figures and future estimates

b. Rank indices $F-9$ and $F-10$ as follows:

Rank

5 Project will provide all missing primary services OR equality with city-wide average ratio of parks/open space to population in the neighborhood.

4 Project will improve primary services or parks/open space to population ratio in the neighborhood.

3 No change in primary services or parks/open space in neighborhood

2 Project will reduce parks/open space ratio or a primary service in the neighborhood.

1 Project will reduce more than one primary service or one primary service AND parks/open space ratio in the neighborhood. 


\section{Primary Analysis (Continued)}

c. Total the rankings and compute the average ranking and refer to scale of impact.

d. If the average ranking is 2.0 or less proceed with Secondary Analysis.

7. Secondary Analysis

a. Community survey of impact area of public hearing at neighborhood association meeting; collection of residents' perceived analysis of impact.

b. Tabulate survey or opinion and rank according to Scale of Impact for this section.

8. Project Reservation Leve1

Scoring below 2.0 


\section{SURVEY FOR SECONDARY ANALYSIS}

In all cases where Secondary Analysis is required the specific section needed should be utilized. While this will not require the total survey to be utilized, it is suggested that in cases requiring Secondary Analysis for at least two or more sections the total survey be administered.

Administration of the test should be under the supervision of City Staff with the participation of neighborhood representatives. It will be important that formal survey procedures are followed. The survey may be conducted either by mail or door-to-door; in either case a representative sample would be required. 


\section{SURVEY}

\section{Project Description}

1. Give a brief description of the nature, intent and area to be impacted by the project.

2. Given the above description please consider the impact of the project on your neighborhood and circle the most appropriate response.

A. Social Health defined as the relative absence of high risk indicators such as crime and mental disorders.

Scale of Impact

5 The project will significantly improve the social health of the community as measured by a reduction in the incidence of high risk indicators.

4 The project will minimally improve the social health of the community.

$3 \quad$ Neutral effect from project.

2 The project will minimally increase social dysfunction as indicated by an increase in high risk indicators.

1 The project will significantly increase social dysfunction as indicated by an increase in high risk indicators. 
B. Heterogeneity/Homogeneity defined as the degree to which community population and lifestyles are similar or dissimilar.

Scale of Impact

5 The project will allow community self determination in an existing heterogenous community.

4 The project will allow community self determination in an existing homogeneous community.

$3 \quad$ Neutral effect from project.

2 The project will not allow community self determination in an existing heterogeneous community.

1 The project will not allow community self determination in an existing homogeneous community.

C. Stability defined as the degree to which the community demographic profile remains the same over the years.

\section{Scale of Impact}

5 The project will maintain the community's social environment.

4 The project will slightly change the community's social environment.

3 The project will moderately change the community's social environment.

2 The project will significantly change the community's social environment.

1 The project will drastically change the 
community's social environment.

D. Cohesion defined as the amount of neighboring

functions and communication between individuals and groups within the community.

Scale of Impact

5 Project will significantly increase neighboring functions.

4 Project will slightly increase neighboring functions.

$3 \quad$ Neutral effect from project.

2 Project will slightly detract from neighboring functions.

1 Project will significantly detract from neighboring functions.

E. Community Problem-Solving defined as the level of community skill and vitality at solving local problems.

Scale of Impact

5 Project will significantly increase community problem solving.

4 Project will slightly increase community problem solving .

$3 \quad$ Neutral effect from project.

2 Project will slightly detract from community problem solving.

1 Project will significantly detract from community problem solving. 
F. Physical Environment defined as the major indicators of the material quality of the community.

Scale of Impact

5 Project will significantly enhance the material quality of the community environment.

4 Project will slightly enhance the material quality of the community environment.

$3 \quad$ Neutral effect from project.

2 Project will slightly detract from the material quality of the community environemtn.

1 Project will significantly detract from the material quality of the community environment. 


\section{SELECTED BIBLIOGRAPHY}

Arnstein, Sherry R. "A Ladder of Citizen Participation" Journal of The American Institute of Planners, Vol. 34, No. 4, July 1969, pp. 216-224.

Be11, Colin and Howard Newby. Community Studies; An

Introduction to the Sociology of the Local Community. New York, Praeger Publishers, 1972.

Bertalanffy, Ludwig von. General Systems Theory: Foundations, Development, Applications. New York. G. Braziller, 1969.

Burdge, Rabel J. and Richard L. Ludtke. "Social Seperation Among Displace Rural Families: The Case of Flood Control Reservoirs", pp. 85-108 in W. R. Burch and Others (eds.), Social Behavior, Natural Resources and the Environment. New York: Harper and Row, 1973 .

Caplan, Gerald. "Conceptual Models in Community Mentàl Heal th". in Caplan (ed.), Support Systems and Community Mental Health. New York: Behavorial Publications, 1974, pp. 245-55.

Christensen, Kathleen. Social Impacts of Land Development: An Initial Approach for Estimating Impacts on Neighborhood Usages and Perceptions. Washington D. C.: The Urban Institute, 1976.

Collins, Alice H. and Diane L. Pancoast. Natural Helping Networks: A Strategy for Prevention. Washington: National Association of Social Workers, 1976.

Cousins, Albert N. and Hans Nagpaul. Urban Man and Society: A Reader in Urban Sociology. New York, Knopt, 1970.

Dunning, C. Mark. "A Systematic Approach to Social Impact Assessment", pp. 59-64 in C. P. Wolf (ed.), Social Impact Assessment. Milwaukee, Wisc.: Environmental Design Research Association, 1974.

Etzioni, Amitai. "Toward a Theory of Guided Societal Change". Social Science Quarterly, Vol. 50, No. 3, December 1969. PP. 749-54. 
Francis, Mark. "The National Environmental Policy Act and the Urban Environment: Toward Socially-oriented Impact Statements". PP. 49-58 in C. P. Wolf (ed.), Social Impact Assessment, Milwaukee, Wisc.: Environmental Design Research Association, 1974.

Gardner, Robert L. "Social Impact Study of the Proposed Willow Creek Flood Control Project". Walla Wa1la, Wash.: U. S. Army Engineer District, Walla Walla, 1973 .

Greer, Scott A. and Ann Lennarson Greer (eds.). Neighborhood and Ghetto: The Local Area in Large-Scale Society. New York, Basil Books, 1974.

Hayden, Bill and Marcy Schwartz. "Development of a Neighborhood Plan". Salem, Oregon: Department of Community Development, May 1975, p. 9 .

Hogg, Thomas C. and Courtland L. Smith. Socio-Cultural Impacts of Water Resource Development in the Santiam River Basin. Corvallis: Water Resources Research Institute, Oregon State University, 1970.

- "Interim Guide for Environmental Assessment", HUD Field Office Edition, McClean, Virginia:

Planning Environmental Internationa1, 1975.

Iscoe, Ira. "Community Psychology and the Competent Community". American Psychologist, Vol. 29, No. 8 August 1974, pp. 607-613.

Ittleson, William H. Environment and Cognition. New York: Seminar Press, $1 \overline{973 .}$

James, L. Douglas and Donna R. Brogan. "The Impact of Open Land on Community We11-Being". Pp. 151-67 in C. P. Wolf (ed.), Social Impact Assessment, Milwaukee, Wisc.: Environmental Design Research Association, 1974 .

James, L. Douglas, Donna R. Brogan, Eugene A. Laurent and Henri Etta Baltimore. Community We11-Being as a Factor in Urban Land Use Planning. Atlanta. Environmental Resources Center, Georgia Institute of Technology, 1974 .

Johnson, Sue and. Rabe1 J. Burdge. "Social Impact State-" ments: A Tentative Approach," pp. 69-84 in C. P. Wolf (ed.), Social Impact Assessment. Milwaukee, Wisc.: Environmental Design Research Association, 1974 . 
Katz, Danie1 and Robert L. Kahn. The Social Psychology of Organizations. New York: John Wiley \& Sons, 1966 .

- "Statewide Planning Goals and Guidelines". Salem, Oregon: Land Conservation and Development Commission, p. 2, December, 1974 .

Leighton, Porthoea $C$. The Character of Danger: Psychiatric Symptoms in Selected Communities. New York: Basic Books, 1963.

Lippitt, Ronald, Jeanne Watson and Bruce Westley. The Dynamics of Planned Change. New York: Harcourt छ Race, 1958.

Llewellyn, Lynn G. "The Social Impact of Urban Highways". PP. 89-108 in C. P. Wolf (ed.), Social Impact Assessment. Milwaukee, Wisc.: Environmental Design Research Association, 1974.

Mack, Ruth P. "Criteria for Evaluation of Social Impacts of Flood Management Alternatives", pp. 175-95 in C. P. Wolf (ed.), Social Impact Assessment. Milwaukee, Wisc.: Environmental Design Research Association, 1974.

Peelle, Elizabeth. "Social Effects of Nuclear Power P1ants", pp. 113-20 in C. P. Wolf (ed.), Social Impact Assessment. Milwaukee, Wisc.: Environmental Design Research Association, 1974.

Ross, Murray G. and B. W. Lappin. Community Organization, Theory, Principles and Practice. New York: Harper ६ Row, 1967 .

Shields, Mark A. Social Impact Assessment: An Analytic Bibliography. Providence, Rhode Island: Brown University, 1974 .

- "Toward a Substance Abuse Policy for Oregon". Salem, Oregon: Interim Human Resources Subcommittee on Alcohol and Drug Abuse 1975-76 Legislative. Assemb1y: State of Oregon, 1976, p. 16.

Steiss, Alan Walter. Urban Systems Dynamics. Lexington, Mass., Lexing ton Books, 1974.

Warren, Roland. The Community in America, Chicago, Rand McNally, 1969. 
Weinberg, Gerald M. An Introduction to General Systems Thinking. New York: John Wiley \& Sons, 1975.

Wolf, C. P. "Social Impact Assessment: The State of the Art." pp. 1-44 in C. P. Wolf (ed.), Social Impact Assessment. Milwaukee, Wisc.: Environmental Design Research Association, 1974. 


\section{APPENDIX A}

SOCIAL IMPACT REVIEW COMMITTEE MEMBERS

Grace Boys

Project Supervisor

Salem Primary Prevention Project

Marion County Community Mental Health

Bi11 Hayden

Community Services Supervisor

Community Development Department

City of Salem

Dan Johnson

District Administration Office

School District 24J

Salem

Kim 01 son

Secretary

Salem Primary Prevention Project

Marion County Community Mental Health

Bertha Roth

Representative, Social Service Commission

City of Salem

JoAnn Runyon

Chairperson, (NESCA)

Northeast Salem Community Association

Jon Spring

Assistant Planner

Community Development Department

City of Salem

Bi11 Triest

Contractor, Social Impact Assessment Tool

Linda Woolley

Chairperson, (SESNA)

Southeast Salem Neighborhood Association 


\section{APPENDIX B}

SOCIAL IMPACT

REVIEW COMMITTEE MINUTES

March 17, 1977

Present: Bill Hayden.......Community Development

Kathy Landreth....Community Development

Linda Woolley.... SESNA

JoAnn Runyon........NESCA

Bertha Roth......Department of Human Resources

Dan Johnson.......Schools

Grace Boys.......Primary Prevention Program

Supervisor

Don Wiesner......Primary Prevention Staff

Kim 0lson........Primary Prevention Staff

Introduction

Bill Hayden brought the meeting to order with a short introductory orientation for those present over what is expected of them in regards to the Mental Health Impact Statement. Bill emphasized that members would be serving on a short-term committee since the impact project is to be completed by June 1, 1977.

\section{Social Impact Review Committee}

Those present requested clarification of their role and function as the Mental Health Impact Steering Committee. It was stressed that the committee had no formal power, rather that it was formed to serve in an advisory capacity by providing general input in the form of questions, clari- 
fication, and ideas.

With a clearer definition of what their role performance is to be, the committee opted to change their name from Mental Health Impact Steering Committee to Social Impact Review Committee. They are expected to meet three to four more times with Bill Triest prior to the June 1st deadline.

\section{Discussion}

Bill passed out several sheets outlining research he's completed thus far, explaining that his goal is to develop a tool which can be used to measure disruption in the community caused by social, economic, political, or physical changes.

Bill emphasized that the field of social impact assessment is relatively a new one. Research and information is scattered and incomplete. However, Bill noted, society's use and awareness of social impact assessment is growing and will hopefully become an instrument to be referred to before any change in implemented in the future.

The community is the key concept around which the Mental Health Impact Statement is to be built. It should be noted that this is no easy matter. There are many different ways of defining what a community "is". For our purposes, Bill has chosen to work with the community as defined by the City's geographical outlay.

Four systems of influence have been picked for impact analysis. They are: social, economic, political, and 
physical. The task is difficult due to both the ambiguity and the arbitrariness of trying to measure the impact each influence of change has upon the community. One must also consider the impact of change deriven from both the interrelationship between systems, and systems when they are overlapping.

Bertha pointed out that although Bill will be making assessments on planned changes, unplanned changes are also occurring which will be very difficult to distinguish. It was noted that because of the great number of variables which can be involved in this work, certain assumptions will have to be made that these things do indeed happen.

Other problems which occur in this type of a study were also noted, such as the differential effect an impact has upon the people in a community. What one person views as being a positive event, may not necessarily be shared by another.

The type and structure of the neighborhoods in a geographically defined community will also lead to different reactions from the population to changes. A neighborhood which is basically transient will not be concerned with the same issues as one in which the residents have lived for years.

Corrections and Additions

Committee members suggested that a cover page be included in the impact analysis which would state in summary 
form what the objectives of the project are, the processes used in developing the instrument, and where the impact statement is to be used. The committee also felt Bill needed to clarify two points of reference; (1) the definition of a healthy community, and (2) what is meant by community well-being. Grace agreed to help Bill with this matter.

By the next meeting, Bili is to devise a list of the baseline and stress indicators that he will be using in developing the impact statement. It was felt that this would be a helpful reference for the tool.

Implementation of the Impact Analysis

Questions were raised as to just how the Social Impact Analysis would be put to use. How was it to be implemented - through training? Who is to introduce its use - the City? Neighborhood?

Most felt the need to encourage a partnership in its use between the City and the neighborhoods. SESNA and NESCA were suggested as possible sites for field testing since they quality as Block Grant neighborhoods.

\section{Closing}

Bill is to continue working on the Impact Statement taking into consideration suggestions made to him by the review committee. When ready he will call another meeting together sometime in the month of April. 
May 18,1977

Present: Linda Woolley, Bill Hayden, Bill Triest, Bertha Roth, Jon Spring, Grace Boys, Dan Johnson, and Kim O1s on

The Social Impact Review Committee held discussion over the materials prepared by Bill Triest for the Mental Health Impact Assessment tool. Several suggestions were made concerning corrections, additions, and/or modifications to the Project Summary and the Operational Definition of Community Well-being. These corrections-additions-modifications are listed below.

\section{Project Summary}

A. An objection was raised to the measurement of community well-being through "achievement and excellence". (Refer to page 2, paragraph 2, second sentence) The committee felt that this statement is too value laden. Standards of achievement and excellence vary from community to community, depending upon such variables as the socio-economic background of the residents, ethnic origin, religious and cultural background, etc. What deems achievement to one will not to another.

B. Also an objection was to the connotation of "happiness and prosperity" used in the definition of community we11-being. (Refer to page 2, paragraph 2 , second sentence) 
The arguments in the above paragraph " $A$ " also pertain to this objection. Consensus was that community we11being depended more upon what was happening in the community and the level of citizen involvement in community affairs. It was noted that there should be some way of measuring the coping ability of a community in reference to its we11-being. Prosperity, happiness, and excellence differ in their degree, depending upon one's coping skills.

\section{Community We11-Being Indices Chart}

A. Committee members expressed some discomfort with the Operational Definition \#3 - Stability. A community is in a constant state of flux. The key to keeping a community healthy and stress free is by maintaining a level of balance within its system. In the operational definition portion, an inferrance is made to the "degree in which the community remains the same". Committee members objected to this statement because they felt that it implied that for a community to be healthy it needed to be stagnate.

B. Refer to \#5 - Community Problem Solving Indices Chart. It was suggested that the use of the Neighborhood. Association as a measuring tool in Community Problem Solving be stricken as it was too limiting. The committee felt that it would be better to open up involvement to any type of community organization. Such 
variables which need to be considered include: how long the organization has been active, how many are involved with the organization, the age of those involved, etc.

C. Refer to \#1 - Health Specific Indices Chart Another measuring tool, number of "high school honor students" was objected to. Social Impact Review committee members expressed dissatisfaction with this as a consideration, claiming that the honor system is not reliable. It varies from one school to the next in its implementation. They felt school indices to be considered should include:

- absenteeism

- attendance

- residency turnover

- transfer rate

- drop-out rate

- involvement in services provided by the school

- activities

Two suggestions were made for additions to the Concept categories:

1. Noise and Nuisance Factors

The degree to which a community is willing to handle its own noise and nuisance problems.

The indicies to be considered could be:

- number of complaints 
- number of times neighbors settle their own problems, or if a mediator is used.

2. Community Contro1

The degree to which a community is autonomous. Indices to be used could be:

- number of locally owned businesses

- number of individually owned businesses

- number of individualiy owned houses

- degree of local funding

- how often the citizens exercise their decisionmaking power

- voter turnout

Jon Spring is to go through Neighborhood Association questionaires with Bill to get a feel of what the major concerns of community populations are in preparation for field testing tool.

Discussion was brought to a close. Bill Triest is to take the developed material and field test it prior to our next meeting which will be sometime between June 15-30. 
July 14,1977

Present: Linda Woolley, JoAnn Runyan, Bill Hayden, Jon Spring, Bill Triest, and Grace Boys

The Social Impact Review Committee met for the final time to review and comment upon the first completed draft: Social Impact Assessment for Community Well-Being. Discussion, revision, and suggestions are as follows:

Overview: Draft is divided into two parts -

Part I. Rationale and Literature Review

Part II. Project Evaluation Tool and Procedures

OUTLINE

SOCIAL IMPACT ASSESSMENT FOR COMMUNITY WELL-BEING

June 28,1977

William H. Triest

Part One. Rationale And Overview

I. Introduction

II. A Review of Social Impact Assessment in Recent Years

III. Building the Assessment Model

A. Prerequisites

Review aims plus prevention of mental disorders plus ease of understanding

B. Systems Approach

C. The Competent Community

D. Community We11-Being 
IV. Indicators of Community We11-Being

A. Social Health

B. Heterogeneity/Homogeneity

C. Stability

D. Cohesion

E. Community Problem Solving

F. Physical Environment

V. Utilization
A. Comments
B. Review of Literature - Partial Listing

Part Two: Project Evaluation Tool for Community We11-Being

I. Introduction

II. Criteria for Test

III. Procedure for Usage

IV. Too1
A. Social Health
B. Heterogeneity/Homogeneity
C. Stability
D. Cohesion
E. Community Problem-Solving
F. Physical Environment

1. $\operatorname{Section}(\mathrm{s})$
A. Operational Definition
B. Goa1
C. Impact of Concern
D. Scale of Impact 
E. High Risk Indices - Data Source - Rank

F. Primary Analysis*

G. Secondary Analysis*

H. Project Reservation Leve1

2. Survey

A. Project Description

A-F see/Scale of Impact

*Primary and Secondary Analysis correlates social indicators with neighborhood perceptions for form more comprehensive judgement.

\section{Emphasis}

From reviewing Part One, group recognized emphasis is placed upon developing the capacity in local communities for problem-solving in relation to issues and facotrs of disruption and/or change. This is consistent with the thrust of primary prevention in mental health practice to increase coping skills and problem-solving abilities.

\section{Utilization}

Is based on application of partnership concept; tool is designed for use by neighborhood residents. Additional benefit of tool is increasing community awareness of mental health factors by heightened participation in assessment process. This was result of recent neighborhood survey in SESNA-increased community awareness. Residents who served as interviewers had opportunity to see how others lived. 
Bill Triest shared with group underlying value assumptions involved in using the tool. This is especially apparent in the scale on heterogeneity/homogeneity - "melting pot" vs. "mosaic" concept and approach. These are problems in resolving value questions with the tool. We are unsure of + or - values to place upon a particular index. Best to let the community decide.

Cohesion

Described Part One, p.11. Definition is too limited needs expansion to include:

$\Delta$ community perception of sense of community

$\Delta$ identification with geographic area

$\Delta$ neighborhood networks - include natural helping, communication, others

Delete second sentence of description and include above. John shared city survey which measures sense of identity with geographic neighborhood which could be utilized with tool.

\section{Future Considerations}

Difficult to come to grips with application of findings of tools. Group recognized limitations of state of the art of Social Impact Assessment. Major benefit in tool will increase information about the social dimensions and provide a systematic framework for looking at effects. Tool is more helpful as Process. 
Tool needs to be acceptable to city and neighborhoodsnecessary sanctions and neighborhood support - in order to be fully utilized. Some possibilities to promote use include: specify need for social assessment in neighborhoods plans and as part of the city Comprehensive Plan; use as basis for citizen participation in planning decisions; incorporate into current neighborhood review of zoning requests.

\section{Next Steps}

Need to get city sanction and neighborhood support to initiate field test for tool and give credibility to effort. Will proceed as follows:

(1) Seek administrative sanction for pilot.

(2) Build neighborhood support for utilization.

(3) Arrange meeting with planning and neighborhood persons to select appropriate Target Project.

Bill Triest will provide revision of tool prior to step number (3). 


\section{APPENDIX C}

FLOW CHART

ASSESSMENT PROCESS

\begin{tabular}{ll} 
STEP & \multicolumn{1}{c}{ TASK } \\
1 & Identification of Impact Project \\
2 & Boundary Analysis of Impact Project \\
3 & Primary Analysis \\
4 & $\begin{array}{l}\text { Review of findings with Impact Area } \\
\text { Residents } \\
5\end{array} \quad \begin{array}{l}\text { Project Approval; mitigation of un- } \\
\text { desired impacts if necessary } \\
6\end{array} \quad \begin{array}{l}\text { Scoring below } 2.0 ; \text { Secondary Analysis } \\
7\end{array} \quad \begin{array}{l}\text { Target Area review of findings } \\
8\end{array} \quad$ Approval or denial by neighborhood
\end{tabular}

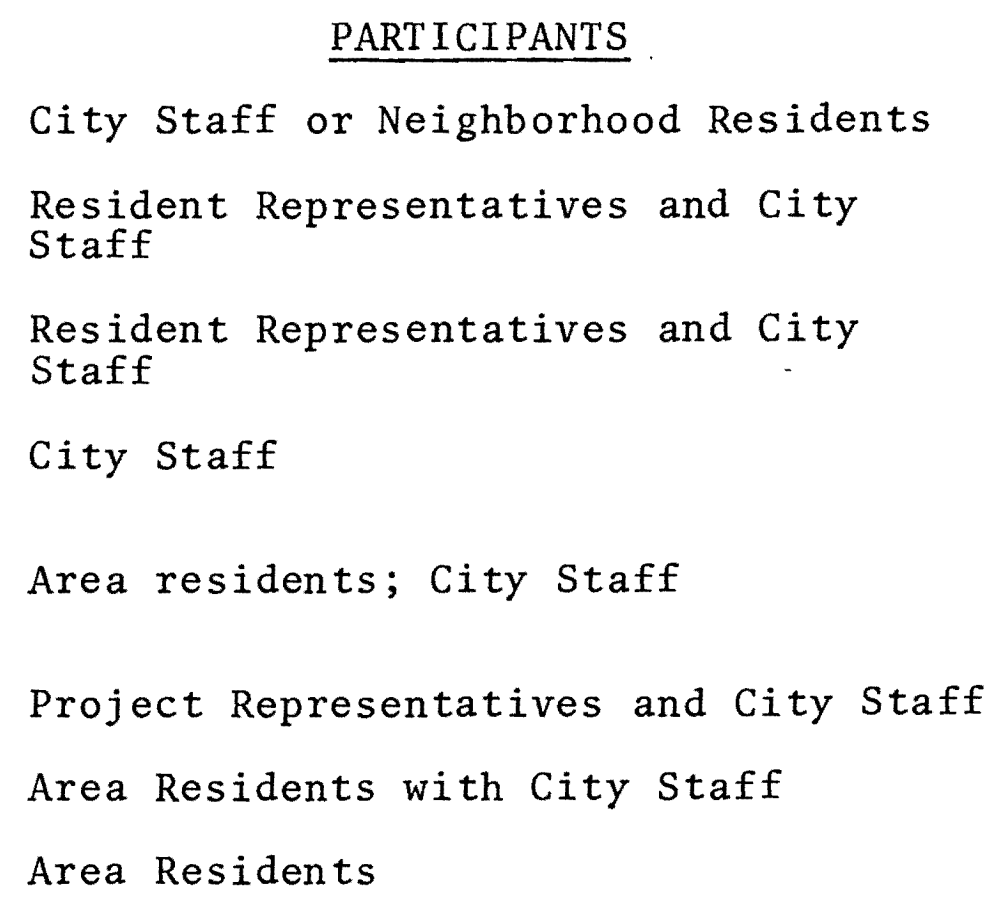




\section{APPENDIX D}

SALEM NEIGHBORHOOD GROUPS 


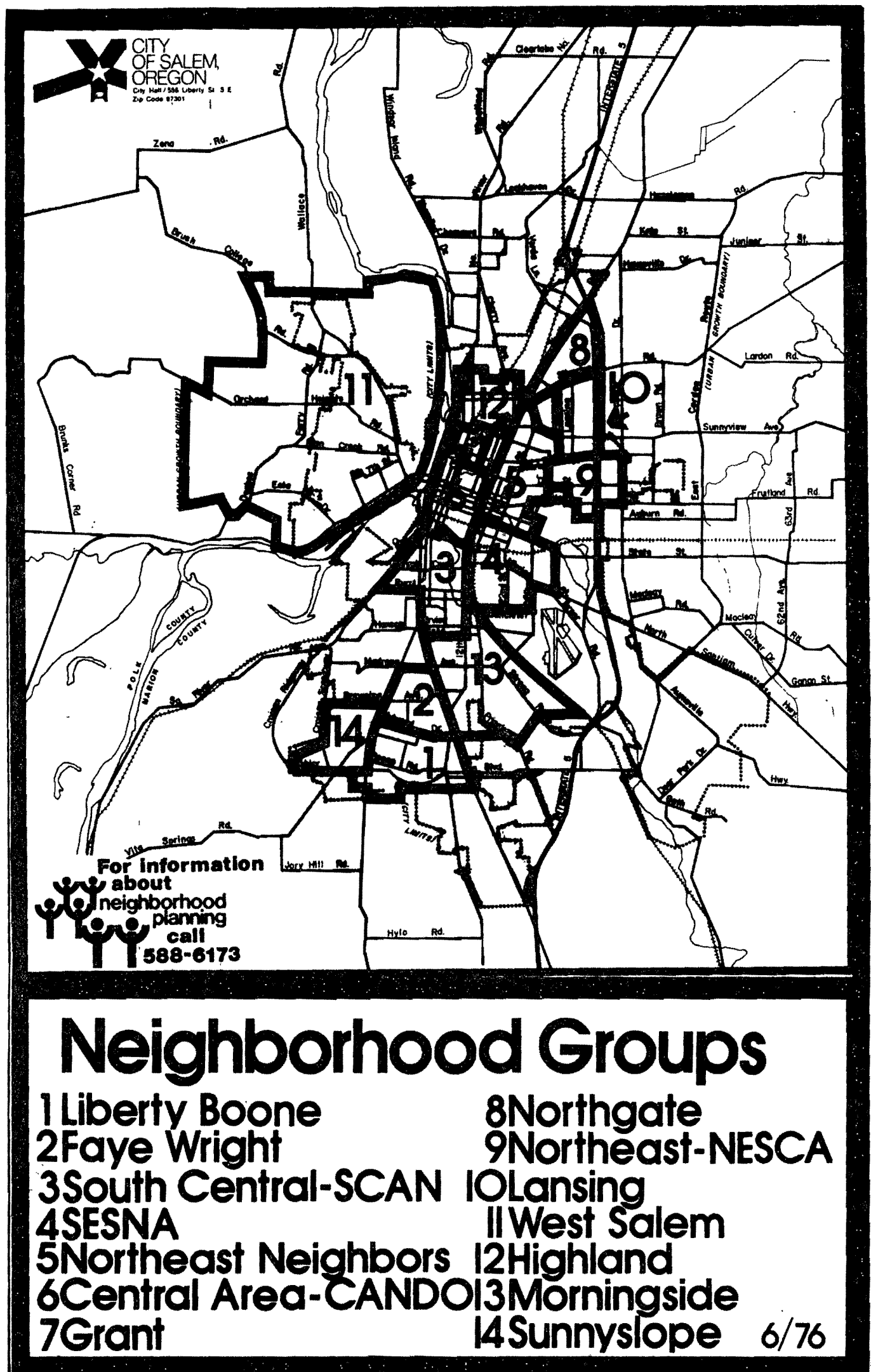

